\title{
Introducing Sustainable Vasectomy Services in Guatemala
}

\section{By Ricardo Vernon, Jorge Solórzano and Blanca Muñoz}

Ricardo Vernon is regional director, Latin America and the Caribbean, of the Frontiers in Reproductive Health program, Population Council, Mexico City. At the time this project was conducted, Jorge Solórzano was the Council's representative in Guatemala, and Blanca Muñoz was project officer, APROVIME, Guatemala City, Guatemala.
The use of contraceptive methods in Guatemala has rapidly increased over the past two decades, from $23 \%$ of married or cohabiting women aged 15-49 in 1987 to $43 \%$ in 2002. The most frequently used method in the country has been female sterilization, used by $11 \%$ of these women in 1987 and by $17 \%$ in 2002 . In contrast, fewer than $1 \%$ of women reported that their partner had received a vasectomy. ${ }^{1,2}$

From a public health perspective, it would be desirable for a greater proportion of couples to adopt vasectomy rather than female sterilization. Vasectomy has a lower rate of postoperative complications than female sterilization, and the client's recovery time is shorter; it is also a less expensive procedure for the providing institution. Furthermore, vasectomy is the only long-term method that men can use to achieve their fertility ideals, and it allows for direct male involvement in reproductive decision making.

\section{BACKGROUND}

The public health sector in Guatemala comprises the Ministry of Health, which provides low-cost services to the uninsured, poor population, and the Guatemalan Social Security Institute (IGSS), which provides a defined package of prepaid services to insured, fee-paying employees and their spouses (or cohabiting partners) and dependents; employers are legally required to register employees with the IGSS. Vasectomies are covered, and the wives or partners of male employees are entitled to receive medical services during pregnancy, birth and the first 40 days postpartum, as well as family planning services (including female sterilization) in the postpartum period; their children are eligible for services up to age five. In the private health sector, APROFAM-the Guatemalan affiliate of the International Planned Parenthood Federation-provides reduced-price reproductive health services to the moderately poor, whereas private, for-profit providers cover the wealthiest Guatemalans. According to the 2002 National Survey of Maternal and Child Health, $74 \%$ of vasectomies were provided by APROFAM, $11 \%$ by private clinics and hospitals, $7 \%$ by the Social Security Institute, $4 \%$ by private physicians and $1 \%$ by the Ministry of Health; for 3\%, the provider was unknown. ${ }^{1}$

*Family planning services for IGSS beneficiaries beyond the 40-day period were reintroduced in 2006, as were vasectomy services.

†lts efforts had not been successful. For example, in 2001 four of its surgeons from three facilities in the Guatemala City metropolitan area were trained to perform vasectomies, yet only 12 procedures were done that year; 24 were performed in 2002 and seven in 2003.
In 2003, the need to improve access to vasectomy services-which the Ministry of Health had been trying to address for several years ${ }^{\dagger}-$ took on new urgency. The obstetrics and gynecology ward of the IGSS hospital in Guatemala City, which had been providing family planning and other reproductive health services to partners of insured males beyond the 40-day postpartum period (even though it had no clear mandate to do so), underwent an administrative change. The new administration terminated all reproductive health services beyond this period, including family planning. Vasectomy services were also halted, meaning that practically all vasectomies were being provided in the private sector.*

In light of these developments, the Ministry of Health recognized that it would need to increase the number of health units offering this service, which would require the training of doctors and health teams. While Ministry service delivery guidelines gave detailed instructions on how no-scalpel vasectomy should be provided in their health units, the provision of materials and equipment needed for the procedure was inadequate. Furthermore, because vasectomy was the least known contraceptive method in Guatemala, potential clients would need to be informed of its availability.

Earlier efforts by the Ministry of Health to introduce vasectomy services had involved sending doctors to hospitals where a relatively high number of vasectomies were being performed; there, the doctor received theoretical training and performed 5-6 operations under expert supervision. Upon returning to their health units, these newly trained providers were given access to the equipment and supplies needed to perform vasectomies, with the expectation that they would immediately begin offering this service. However, since this program did not include the promotion of vasectomies to potential clients, demand was usually low; therefore, the doctors performed few vasectomies and sometimes stopped offering them after a short period. Over time, these providers lost their initial enthusiasm, as well as the skills needed to perform the procedures safely. Hence this program proved ineffective in creating sustainable vasectomy services. In addition, it was costly: With few Guatemalan health units having sufficient caseloads, doctors often had to be sent to other countries for training, or needed to stay at the training site for extended periods of time.

\section{THE SUSTAINABLE VASECTOMY SERVICES MODEL}

To increase the availability and use of vasectomies, the Ministry of Health and the Population Council's Frontiers in Reproductive Health program (FRONTIERS) developed, 
tested and evaluated a model for the introduction of sustainable no-scalpel vasectomy services in Ministry hospitals and maternities. The plan was to introduce the service in a minimum of four hospitals or clinics, with the goal that at least one would have a large enough caseload to become a training center. APROVIME, a Guatemalan nongovernmental organization, provided administrative support for the project.

The model was adapted from one successfully used by the Mexican Social Security Institute ${ }^{3}$ and from the experiences gleaned in other operations research projects implemented in Guatemala over the past few years. The model had four basic elements: selection of health units that identified at least one vasectomy candidate before starting training activities; development of a counseling and information program for potential clients; training of health teams; and on-site training of doctors.

\section{Selection of Service Delivery Units}

To identify service delivery units whose employees were likely to be motivated to implement the proposed activities, the Ministry and FRONTIERS selected 15 hospitals and maternities near Guatemala City from among those with the largest volume of prenatal visits, deliveries and female sterilizations in the years 2003 and 2004. Between October 2004 and July 2005, project staff visited each of these facilities and described the project to the hospital director and health team, explaining that to be eligible for training, they had to identify at least one man who was interested in having a vasectomy.

Two hospitals refused to participate in the project. The directors of the remaining 13 units stated their interest in participating and accepted the project requirements. However, only six of the directors later contacted the project's field coordinator to inform her that they had identified at least one vasectomy candidate and were ready to begin training activities. Thus, the requirement of identifying a vasectomy candidate was effective in screening out unmotivated managers.

\section{Development of a Counseling and Information Program}

To develop the counseling and information component of the project, Ministry and FRONTIERS staff examined results from several Latin American studies, which showed that men who choose vasectomy are typically $30-40$ years old, are married or in a consensual union, live in large cities, and have a stable job, a higher-than-average level of education and relatively small families; furthermore, they have used various temporary contraceptive methods, to a large degree those that require the participation of males, and are tired of doing so. ${ }^{4,5}$ These studies have also shown that men who choose vasectomy receive information from multiple sources throughout the stages of deciding whether to undergo the procedure. In the first stage, they learn about vasectomies from their partners, health service providers, mass media, friends and relatives. In the second stage, men seek more information by speaking with friends and men who have had a vasectomy, by reading leaflets and other materials, and by consulting health service providers. In the third stage, men make the decision after discussing it with their partner and comparing vasectomy and female sterilization. Most men report that their partner was the most influential person in their decision-making process. ${ }^{4,5}$

Because the Ministry of Health does not have a budget for mass media advertising, the project's staff decided that the most feasible strategy for reaching men who were potentially interested in a vasectomy was to prepare printed materials designed for men with these characteristics, and to distribute the materials to men visiting Ministry hospitals and clinics, and to women who had just delivered a baby and who requested female sterilization. Later, vasectomy acceptors from the project were invited to promote the method by providing printed materials to their friends and relatives.

We developed four types of materials: a leaflet describing benefits of vasectomy, to be handed out to men in hospital waiting rooms and in communities; a poster presenting benefits of vasectomy, to be placed in hospitals and clinics to inform attendees of the availability of the method; a color brochure comparing vasectomy to female sterilization, to be given to women (for discussion with their partner) who showed an interest in permanent methods during postpartum family planning talks or in counseling sessions; and two large street banners announcing that the method was available, to be displayed outside participating hospitals. Project records show that hospital staff distributed 10,659 leaflets and 7,169 comparative brochures, and displayed an average of three posters each month. Service providers collected data on the people who received materials. These data show, however, that only a small proportion of the materials were given to people with the characteristics of typical vasectomy acceptors.

\section{Training of Health Teams}

In contrast to the vasectomy introduction model used previously in Guatemala, in which only the doctor was trained, this model included a training component aimed at all personnel from the six participating hospitals and 24 nearby health centers and posts that could serve as referral centers for patients. The expectation was that staff members would inform clinic and hospital users about the availability of vasectomy services and thus help recruit potential clients.

One four-hour workshop was conducted at each site. Participants included 105 doctors, 91 nurses, 386 nurse auxiliaries, 20 social workers and 122 other employees, such as statisticians, secretaries and doormen. Workshop leaders described the project and covered a number of topics: the procedure of no-scalpel vasectomy, the importance of counseling clients about all contraceptive methods, how staff should use and disseminate the promotional materials, how to refer patients, how to collect the data that project staff would use for evaluation (e.g., characteristics of those receiving materials, requesting services and undergoing the procedure) and how to obtain clients' informed consent. For each unit, an action plan was drafted for activities that were to be conducted in subsequent months, 
such as the number of talks to be given in different hospital areas and the numbers of the various types of promotional materials to be distributed. Participants completed questionnaires both before and after the workshops; although they had adequate information about vasectomy before the training, they were more knowledgeable afterward. The two weakest areas were the need to use a contraceptive method for the first three months or 20 ejaculations after the procedure, and the typical characteristics of men who choose vasectomy.

\section{On-Site Provider Training}

To be eligible for training in the no-scalpel vasectomy technique, candidates had to be general practitioners or specialists with some experience in general surgery, ${ }^{*}$ and be willing to identify and recruit men who wanted a vasectomy. Surgical training took place in candidates' own health units and occurred in two stages: theoretical training and practical on-site training.

Theoretical training involved a half-day session, which covered Ministry of Health service delivery guidelines, existing vasectomy techniques, postoperative precautions and recommendations to be given to the client before and after surgery, promotional strategies that each team had to implement and maintenance of project records. Participants also watched a video on the no-scalpel vasectomy technique. The first theoretical training session was conducted in November 2004 for a group of doctors from four hospitals; later sessions were provided individually as more physicians requested training in January, March and August of 2005.

In the practical on-site training, participants performed a number of vasectomies under the trainer's supervision; these sessions occurred when health teams had identified three or more vasectomy clients and scheduled the surgeries. In the initial session, the trainer would usually perform the first vasectomy (or half vasectomy, in which the trainer would locate and ligate the first vas deferens and allow the trainee to do the same with the second one). Subsequent vasectomies were performed by the trainee under the observation of the trainer, who would intervene if the trainee could not carry out a particular step. A checklist was used to ensure that the surgical protocol was followed. These supervised surgeries continued until the trainer determined that the trainee had the skills and knowledge to perform the operations alone, and the trainee felt confident in his abilities to do the procedures. The trainer returned to the hospital for as many surgery sessions as needed for the trainee to achieve certification.

\section{PROJECT OUTCOMES}

Five aspects of this project were evaluated: the feasibility of training surgeons at their home health unit, the number of surgeons trained, the number of vasectomies performed,

*In Guatemala, all medical students receive some surgery training. General practitioners in hospitals often conduct simple surgical procedures, such as reduction of fractures, cesarean sections, appendectomies, hysterectomies and other abdominal procedures, which they learn on the job. the effectiveness of the promotional strategies and an analysis of costs. Service records were used to evaluate the first three variables, and promotional effectiveness was assessed using data collected in interviews with the project's vasectomy acceptors. Project accounting books and Ministry of Health records were used to estimate program costs.

\section{Training and Vasectomies Performed}

Of the 19 doctors who attended theoretical training, only 14 began practical training (i.e., performed at least one supervised vasectomy). Of these 14, eight had been certified and four were still being trained when the project concluded on September 30, 2005 (when we also ended the followup observation period for the certified doctors). Two doctors who began practical training decided not to continue, preferring that other doctors in their service delivery units be trained instead. In a follow-up visit in November 2006, two of the four doctors who had not completed training by the end of the project had been certified by the Ministry of Health; the other two no longer worked in their units, and no information was available on whether they had completed the training.

During the project, 158 vasectomies were performed in 54 training or surgical sessions, with an average of 2.9 vasectomies per session. The eight certified providers performed 140 vasectomies, whereas the four physicians who were still training at the end of the project performed six; the trainer performed the remaining 12 . Six hospitals and maternities participated in the project, including two at which no providers had been certified to perform vasectomies without supervision (they were incorporated into the project a few months before its end).

Of the eight physicians certified as no-scalpel vasectomy providers, three were general practitioners and five were obstetrician-gynecologists (Table 1). The overall trainingfrom first practice session to certification-lasted an average of 12.1 weeks; when the doctor from Zone 19 of the Guatemala City metropolitan area (who required 24 weeks) was excluded, the average was 10.5 weeks (not shown). Providers required an average of 3.8 training sessions and 8.3 vasectomies to be certified; after excluding the Zone 19 doctor (who took seven sessions and 22 operations to be certified), the average provider required 3.3 sessions and 6.3 surgeries to be certified (not shown). (Sessions were of variable duration, and lasted until all scheduled vasectomies were performed; data were not collected on the duration of sessions, but the time per procedure decreased substantially as trainees acquired practice.)

The four hospitals and maternities continued to deliver vasectomy services after their doctors were certified: Seventy-four vasectomies were performed in 28 postcertification sessions. The Zone 19 doctor was highly productive, performing 42 vasectomies in four sessions after certification. In contrast, the other seven doctors performed 32 surgeries in 24 sessions. Over the project period, each center had about one monthly session after certification.

These four facilities continued to provide vasectomies 


\begin{tabular}{|c|c|c|c|c|c|c|}
\hline $\begin{array}{l}\text { Hospital and provider } \\
\text { type }\end{array}$ & $\begin{array}{l}\text { Wks. from first } \\
\text { practice session } \\
\text { to certification }\end{array}$ & $\begin{array}{l}\text { No. of } \\
\text { training } \\
\text { sessions }\end{array}$ & $\begin{array}{l}\text { No. of } \\
\text { vasectomies } \\
\text { before } \\
\text { certification }\end{array}$ & $\begin{array}{l}\text { Wks. from } \\
\text { certification } \\
\text { to project } \\
\text { end }\end{array}$ & $\begin{array}{l}\text { No. of surgery } \\
\text { sessions from } \\
\text { certification } \\
\text { to project end }\end{array}$ & $\begin{array}{l}\text { No. of } \\
\text { vasectomies } \\
\text { after certification }\end{array}$ \\
\hline \multicolumn{7}{|l|}{ Amatitlán } \\
\hline General practitioner & 9 & 3 & 8 & 24 & 4 & 4 \\
\hline General practitioner & 9 & 5 & 9 & 24 & 3 & 6 \\
\hline \multicolumn{7}{|l|}{ Chimaltenango } \\
\hline General practitioner & 9 & 2 & 7 & 20 & 3 & 3 \\
\hline Obstetrician-gynecologist & 9 & 3 & 4 & 32 & 3 & 4 \\
\hline \multicolumn{7}{|l|}{ Zone 18} \\
\hline Obstetrician-gynecologist & 13 & 3 & 6 & 26 & 3 & 5 \\
\hline Obstetrician-gynecologist & 11 & 4 & 4 & 19 & 4 & 5 \\
\hline Obstetrician-gynecologist & 13 & 3 & 6 & 15 & 4 & 5 \\
\hline \multicolumn{7}{|l|}{ Zone 19} \\
\hline Obstetrician-gynecologist & 24 & 7 & 22 & 19 & 4 & 42 \\
\hline Total & 97 & 30 & 66 & 179 & 28 & 74 \\
\hline Average & 12.1 & 3.8 & 8.3 & 22.4 & 3.5 & 9.3 \\
\hline
\end{tabular}

Note: Includes only procedures performed by trainees who were certified by the end of the project period.

during the 12 months after the project was completed, despite almost no supervision, little support and lack of informational and promotional materials. The maternity in Zone 19 continued to be the most productive center, with 78 vasectomies performed (not shown). Its caseload was high enough to allow it to function as a vasectomy training center, as it attracted enough clients to train two or three providers in about three sessions. At the 12-month followup, the maternities in Zone 18 and Chimaltenango had provided 22 and 11 vasectomies, respectively, whereas the hospital in Amatitlán had provided only four. By this time, the Ministry of Health had trained three more physicians in project facilities and four were in training.

A review of the protocol checklists used by the trainers showed that during their first three vasectomies, 58\% of trainees competently performed all the steps required prior to the procedure: checking biographical information, determining whether the clients had made a definite decision, repeating pertinent information on informed consent and conducting a physical examination. By the fourth supervised operation, $78 \%$ of trainees had mastered these requirements.

The most difficult steps in the surgical technique were finding the vas deferens percutaneously and ligating the contralateral vas deferens: Forty percent of surgeons performed these steps competently in the first two practice surgeries, and $58 \%$ did so in the third. Most trainees required six or seven supervised vasectomies to gain competence and to acquire the confidence to perform the procedure without supervision. Trainees said the most difficult steps were isolating the first vas deferens and delivering the second vas deferens to the incision made in the scrotum.

Only five, minor cases of secondary effects were detected during the project; all of them resolved without further complications. Patients were given follow-up appointments for eight days after the operation, and were asked to come back at three months for a semen analysis to verify the success of the vasectomy; however, few patients returned for this last appointment.

\section{Effectiveness of Promotion Strategies}

To evaluate the effectiveness of the various channels of promotion, we asked vasectomy acceptors where they had gotten information about the procedure and which source had had the greatest influence on their decision. Fifty-three percent had read either a project brochure or poster, or both, and $42 \%$ had learned about vasectomy from newspapers, magazines, books, radio or television. Partners were the most consulted source and also the most influential: Sixtyeight percent of men said they had spoken to their partner during the decision-making process, and $41 \%$ said she had had the most influence on their decision to get a vasectomy. Health providers were cited by $31 \%$ of men, and were the most influential source for $9 \%$. Friends, relatives and vasectomized men were sources for $21 \%$ of acceptors, and were the most influential source for $6 \%$. Nevertheless, $81 \%$ said they knew at least one man who had had a vasectomy, underlining the importance of acceptors as sources of information or as examples.

Sources for referral to the hospital where they had the operation were also diverse: Twenty-nine percent named their partner, 38\% personnel from the same hospital, 25\% personnel from other health centers, and $18 \%$ friends or relatives. Fewer than $10 \%$ of the men mentioned other sources.

The facility with the most success in attracting vasectomy patients was the maternity in Zone 19 of Guatemala City. The doctor and the nurse auxiliary in charge of promotion attributed their success to daily family planning talks for 
women who had just delivered a baby. At these talks, staff presented information on vasectomy, handed out the brochure comparing vasectomy to female sterilization and encouraged women to discuss the issue with their partners. Another factor cited was the involvement of all unit personnel, since even the doorman sometimes provided information to persons who were reticent about requesting information from counselors in a more formal manner. Other significant components were the distribution of materials, talks with men in waiting areas and referrals from satisfied clients.

Project data also supplied evidence that providing information on vasectomy to women in the immediate postpartum period is important: Fifty-six percent of vasectomy acceptors had a child younger than one, $69 \%$ had made the decision to have a vasectomy in two months or less, and $65 \%$ mentioned their partner's health as a reason for preferring vasectomy to female sterilization.

\section{Cost Analysis}

APROVIME and the Ministry of Health have different salary and expense structures, so cost estimates were derived using both the actual salary, travel, per diem and printing costs incurred by APROVIME to introduce vasectomy at the service delivery sites and the lower Ministry costs for these expenses. * Because eight doctors were certified as vasectomy providers during the project and two achieved certification a few months after the project ended, this cost analysis included all 10 trained providers.

The total cost of the project incurred by APROVIME, including instructor and coordinator costs, was US $\$ 43,355$; the average cost per trained provider was $\$ 4,335$, or $\$ 274$ per vasectomy performed. If the trainees' (doctors and health teams) salaries and expenses are excluded, the total cost would be $\$ 29,301$, for an average of $\$ 2,930$ per trained surgeon and $\$ 185$ per vasectomy. If we use the Ministry salary and expense structures, the total cost of the project would be $\$ 29,204$; it would be $\$ 17,158$ without the cost of trainees' time. Although these costs are high, they are substantially lower than the average direct costs of US $\$ 5,000-$ $\$ 7,000$ (i.e., not including trainee time) of sending doctors to be trained in other countries.

The project's most expensive component was the training of health teams. Training personnel in 30 health units cost nearly $\$ 20,000$ (including trainees' time, per diem expenses and materials), almost half the cost of the project. If only the teams from the six units that delivered vasectomy services had been trained, then the training costs for teams would have been approximately $80 \%$ lower.

The theoretical and practical training of providers was relatively inexpensive. If coordination visits are not taken into account, the cost for these training sessions would be US $\$ 8,935$, or about $\$ 900$ per trained provider (about $\$ 500$

*For example, APROVIME paid instructors US\$150 and project coordinators $\$ 72.85$ per day, while the Ministry paid instructors and coordinators $\$ 54$ and $\$ 22.50$ per day, respectively. APROVIME and Ministry per diem expenses were $\$ 40$ and $\$ 20$, respectively. using the Ministry cost structure). If the postcertification follow-up costs are included, then the average cost per trained provider would be about $\$ 1,680$ (about $\$ 880$ using Ministry rates). Finally, the cost for promotion and providing information to users was about $\$ 550$ per hospital (including design and printing of materials, nurses' time for giving talks at six hospitals and distribution of materials at these hospitals and 24 health centers).

If the Ministry of Health were to replicate this vasectomy introduction model, direct costs would be greatly reduced, since the Ministry has lower salary and expense structures. Expenses for the design of materials could also be avoided (because they have already been developed), and the costs of coordination visits could be reduced (because the Ministry has supervisors and staff in many locations). In addition, the training of health teams in nearby health centers could be eliminated without greatly affecting the number of vasectomy candidates. Furthermore, because the Ministry trainers would be located closer to trainees' sites, and because the number of men requesting vasectomy would probably increase as the promotion and acceptance of the method grew, the costs for provider training would likely decline.

\section{RECOMMENDATIONS}

Like other experiences in less developed countries, this project demonstrated that vasectomy can be successfully introduced into the contraceptive method mix promoted by public-sector family planning programs. Our experience suggests the desirability of screening out health units that lack the motivation or ability to implement the required activities, the importance of including the trainee's self-confidence in performing the procedure as a criterion for certification, the feasibility of conducting on-site training and the effectiveness of encouraging hospital employees to identify vasectomy candidates. Presenting-in the immediate postpartum period-vasectomy as an option to women who desire a permanent contraceptive method is also important.

Some recommendations for improving the effectiveness of a vasectomy introduction model include performing the procedures on Fridays after 11:00 a.m. or on Saturday morning, to allow men to rest over the weekend and so avoid the need to miss more than half a day of work; reinforcing counseling and establishing reminder mechanisms to improve the proportion of clients who return for a semen analysis three months after their vasectomy; and advising trainees to practice identifying the vas deferens (the most difficult step in the procedure) on their own bodies or on anatomical models. Other successful vasectomy providers in Latin America, such as the Mexican Social Security Institute, have a longer provider certification process, requiring that trainees perform 20 unsupervised operations after completing their practical training and that instructors visit them to ensure that they are following the surgical protocol. Such followup visits can strengthen the surgeon's abilities and the health team's motivation to promote the method, even if fewer unsupervised procedures are required for certification. 
We also recommend reducing the costs of training health teams in nearby health centers by inviting one member to attend the training at the hospitals and encouraging them to replicate the materials and training at their own units. Furthermore, in this project we invited vasectomy acceptors to a promotion training meeting, but very few showed interest or attended. It might be more effective to simply give them printed materials and invite them to inform friends who might be interested in the method.

\section{REFERENCES}

1. Ministerio de Salud Pública y Asistencia Social (MSPAS) et al., Guatemala Encuesta Nacional de Salud Materno Infantil (ENSMI) 2002, Guatemala City, Guatemala: MSPAS, 2003.

2. MSPAS, Instituto de Nutrición de Centro América y Panamá (INCAP) and Institute for Resource Development/Westinghouse, Guatemala Encuesta Nacional de Salud Materno Infantil 1987, Guatemala City, Guatemala: INCAP, 1989.

3. Juárez C, Using a systems approach to expand vasectomy services: the experience of the Instituto Mexicano del Seguro Social, paper presented at Vasectomy: New Evidence About a Long-standing Method, Washington, DC, Dec. 4-5, 2003

4. Foreit K, de Castro MPP and Duarte Franco EF, The impact of a massmedia advertising on a voluntary sterilization program in Brazil, Studies in Family Planning, 1989, 20(2):107-126.

5. Vernon R, Operations research on promoting vasectomy in three Latin American countries, International Family Planning Perspectives, 1989, 22(1):26-31.

\section{Acknowledgments}

This project was funded by the U.S. Agency for International Development under cooperative agreement HRN-A-00-98-00012 with Frontiers in Reproductive Health, Population Council. Technical and administrative support were provided by Frontiers and APROVIME, respectively. The views expressed here are those of the authors and not necessarily those of the funder.

Author contact: rvernon@popcouncil.org.mx

\section{Statement of Ownership, Management and Circulation}

Title of publication: International Family Planning Perspectives. Publication no.: 404170. Date of filing: Sept. 17, 2007. Frequency of issue: Quarterly. No. of issues published annually: Four. Annual subscription price: Individuals, $\$ 40.00$; Institutions, $\$ 50.00$. Complete mailing address of known office of publication: 125 Maiden Lane, New York, NY 10038. Complete mailing address of the headquarters or general business offices of the publisher: Same as above. Publisher: Guttmacher Institute, same address as above. Editor: Patricia Donovan, same address as above. Owner: Guttmacher Institute. Known bondholders, mortgagees, and other security holders owning or holding 1 percent or more of total amount of bonds, mortgages or other securities: None.

The purpose, function, and nonprofit status of this organization and the exempt status for federal income tax purposes have not changed during the preceding 12 months.

\begin{tabular}{|c|c|c|}
\hline $\begin{array}{l}\text { Extent and nature } \\
\text { of circulation }\end{array}$ & $\begin{array}{l}\text { Avg. no. } \\
\text { copies } \\
\text { each } \\
\text { issue } \\
\text { during } \\
\text { preceding } \\
12 \text { mos. }\end{array}$ & $\begin{array}{l}\text { Actual no. } \\
\text { copies of } \\
\text { single } \\
\text { issue } \\
\text { published } \\
\text { nearest to } \\
\text { filing date }\end{array}$ \\
\hline Total no. copies & 27,875 & 28,000 \\
\hline $\begin{array}{l}\text { Paid and/or } \\
\text { requested circulation } \\
\text { Sales through dealers } \\
\text { and carriers, street ven- } \\
\text { dors, and counter sales }\end{array}$ & 0 & 0 \\
\hline $\begin{array}{l}\text { Mail subscription } \\
\text { (paid and/or requested) }\end{array}$ & 27,510 & 27,635 \\
\hline $\begin{array}{l}\text { Total paid and/or } \\
\text { requested circulation }\end{array}$ & 27,510 & 27,635 \\
\hline $\begin{array}{l}\text { Free distribution by mail, } \\
\text { carrier or other means; } \\
\text { samples, complimentary } \\
\text { and other free copies }\end{array}$ & 0 & 0 \\
\hline Total distribution & 27,510 & 27,635 \\
\hline $\begin{array}{l}\text { Copies not distributed } \\
\text { Office use, left over, } \\
\text { unaccounted for, spoiled } \\
\text { after printing }\end{array}$ & 365 & 365 \\
\hline Return from news agents & 0 & 0 \\
\hline Total & 27,875 & 28,000 \\
\hline $\begin{array}{l}\text { Percent paid and/or } \\
\text { requested circulation }\end{array}$ & $98.69 \%$ & $98.69 \%$ \\
\hline \multicolumn{3}{|c|}{$\begin{array}{l}\text { I certify that the statements made by me above are } \\
\text { correct and complete. }\end{array}$} \\
\hline
\end{tabular}
Editor 